\title{
Model of Lean tools for the reduction of waste in the manufacture of non-metallic minerals
}

\author{
Piero Abanto ${ }^{1}$, Carlo Guzmán ${ }^{1}$, Edgardo Carvallo, Msc $^{1}$, Iliana Macassi, Msc ${ }^{1}$, and Christian del Carpio, Msc ${ }^{2}$ \\ ${ }^{1}$ Industrial Engineering, Universidad Peruana de Ciencias Aplicadas (UPC), Lima - Peru, u201521035@upc.edu.pe, \\ u20141a496@upc.edu.pe, edgardo.carvallo@upc.pe, pcadlmac@upc.edu.pe \\ ${ }^{2}$ Direction of research, Universidad Peruana de Ciencias Aplicadas (UPC), Lima - Peru, pcelcdel@upc.edu.pe
}

\begin{abstract}
The present paper presents a model that combines tools such as SLP (Systematic Layout Planning), 5's, Standardization of methods and Preventive Maintenance for the reduction of waste in the manufacture of non-metallic minerals. This RMI (Industrial Rocks and Minerals) production sector has a high growth potential. Around 5 to 20 million tons were produced in the 70s, 80s and 90s, and it increased between 25 and 100 million tons annually in the present millennium in Peru. The problem to be attacked is the high amount of material that is wasted in the production process in small and medium-sized companies in the RMI production sector. With the validation carried out on our model, results of a reduction of material waste from 135.1 tons / year to 55.6 tons / year were obtained. This meant a waste reduction of $58.8 \%$. The implementation of 5 's until the standardization stage, indirectly impacted the other components. The result obtained with the layout redesign model was from 46.1 tons / year to 16.32 tons / year (65\%), the redesign reduces the travel distances with material, which generates less waste in transport. In addition, a reduction of 35 tons / year to 10.5 tons / year (70\%) is validated with the pilot testing of the definition and standardization of the prior rock breakage method. Also, the preventive maintenance pilot testing to the cyclone dust extractor, reduced the machine stops and validated than waste is reduced from 54 tons / year to 28.8 tons / year (46.7\%).
\end{abstract}

Keywords-- Lean Manufacturing, waste reduction, non-metallic mining, preventive maintenance, 5's, standardization of methods, systematic Layout Planning

\section{INTRODUCTION}

Peru has an interesting geological potential of various RMIs (Industrial Rocks and Minerals). In 1970, according to studies sponsored by INGEMMET, 367 occurrences and quarries of RMI were recorded. In December 2017, they add 4964 what it means, an increase in 13.52 times. It is estimated that, from a production of around 5 to 20 million tons per year in the $70 \mathrm{~s}, 80 \mathrm{~s}$ and $90 \mathrm{~s}$, it increases on average from 25 to 100 million tons annually in the present millennium. This growth over the past 47 years has placed Peru as an interesting country for investment in Latin America. [1] Developing economies in Africa, Asia and the Pacific, Latin America and West Asia are in great need of additional investments in infrastructure. And, as a consequence, the extraction of non-metallic minerals (used in infrastructure) per capita and per dollar grew steadily during the period from 1970 to 2010 [2].

Digital Object Identifier (DOI):

http://dx.doi.org/10.18687/LACCEI2020.1.1.171

ISBN: 978-958-52071-4-1 ISSN: 2414-6390
However, in order to be able to use these non-metallic minerals as the main input in the different industries, it is necessary to go through a manufacturing process, where the size is reduced to standardized particles according to the number of granulometry required. That is why is it analyzed the nonmetallic mineral manufacturing sector, which maintains a 5\% waste percentage in its manufacturing processes today [3]. However, for small businesses it is impossible to keep waste below that percentage. The problem is relevant since the nonmetallic mineral manufacturing sector has developed very slowly in Peru because it is mostly managed by small and medium-sized companies, which do not have the necessary capital to be able to acquire top-level machinery and position their products on larger scales and at better prices [4].

In this manner, emphasis is placed on the waste generated in the mills of the calcium carbonate mineral, since they emit a large amount of powders in their crushing, sieving, transport and handling processes, which can occur in any dimension. It should be noted that the fine powder of calcium carbonate is the main waste generated in the production of carbonate granulometry due to the ease with which it is emitted. Therefore, the collection, quantification and use of this input is important, because it has an important role in some manufacturing sectors such as the production of cement, paints and ceramics [5]. This is important because the global demand for products derived from RMIs increases inexorably with economic growth and developing prosperity [6].

This article proposes a model that uses tools such as standardization of methods, SLP, 5's and preventive maintenance in order to reduce material waste in the production process of grinding non-metallic minerals. The development is divided into 6 sections. The second is the state of the art, which consists in the description of success stories in which the proposed tools have been implemented and / or developed. The third section is the contribution which contains the project model, the phases of the proposal development and the indicators with which the results of each tool will be measured. The fourth section contains the validation, in this section the expected results will be validated based on the indicators. The fifth section contains the conclusions on this article.

\section{STATE OF ART}

This is divided into 5's and preventive maintenance, and plant distribution with standardization of methods.

$1^{\text {th }}$ LACCEI International Multi-Conference for Engineering, Education, and Technology: "Engineering, Integration, and Alliances for a Sustainable Development" "Hemispheric Cooperation for Competitiveness and Prosperity on a Knowledge-Based Economy", 27-31 July 2020, Virtual Edition. 


\section{A. 5's and Preventive Maintenance}

These tool and philosophy are generally applicable to all manufacturing companies, and in the case of the non-metallic mining sector it is a good opportunity for its application, as developed in the following success stories.

Willison in [7] used the $5 \mathrm{~S}$ tool as part of the Lean initiative in manufacturing facilities of manufacturing companies in India. Several changes were made to the operating procedures, the organization of the tools, the cleaning programs and the handling of materials. In a case study, there is the need to demonstrate that $5 \mathrm{~S}$ techniques would strongly support the objectives of an organization to achieve greater performance and continuous improvement. They conducted a 5-year audit, an action plan for each of the 5 through activities, ordering, ordering, cleaning, standardizing and maintaining discipline. This tool generates benefits, such as improving the quality of products or services, in the work environment, reducing costs, increasing efficiency, reducing waste, etc [8].

Improvement of productivity indicators should be made, keeping the entire production system within the OEE (Overall Equipment Effectiveness) indicators, proposing pillars of implementation, so that organizations are more productive [9]. The results with the implementation of " $5 \mathrm{~S}$ ", improved the tool search time. Workshop tool search time has been reduced from 30 minutes to 5 minutes. This time difference, brought a monthly saving of 416 rupees to the company. The result was the reduction of the decomposition time and, therefore, increased the overall effectiveness of the equipment and, therefore, reached the highest productivity. The 7\% increase in OEE is achieved after the implementation of preventive maintenance within a month of theese activities.

\section{B. Plant distribution and Standardization of methods}

An incorrect plant distribuitions translates into waste, such as censer transfers, discomfort for the worker, exceeded times, bad material handling. Therefore, many improvement projects in small plants have been considered not very viable, because of the little space and very little attention at the beginning of the design process to the space requirements. In a case study in the United States they proposed a redistribution model based on the SLP methodology, in order to promote safe operation in all phases, Maximize operability, Maximize accessibility, Minimize construction costs, Minimize construction costs Maintenance and Minimize the space required.

In plant distribution projects, the optimal use of resources is emphasized through an adequate disposition of the space, in which the operators and all those involved feel comfortable to be able to develop their activities free of restrictions [10]. In addition, it involves the standardization of work incorporated into the $5 \mathrm{~s}$ philosophy, the activities of classification, order, cleaning, should be activities that generate a better work environment with specific activities aimed at reducing errors and operational variability [11]. For this reason, the manufacturing of non-metallic minerals should be aligned, because there are various factors of relationship of the areas, such as noise, pollution, distances traveled and handling of materials that could be great opportunities for improvement that arise from an adequate plant distribution. Part of this is also the correct functioning of this, through a correct standardization of working methods.

In a case study in India in 2016, excessive delivery time was determined as the main problem without affecting current work systems in an automotive component manufacturing industry. The VA (Value Added) and NVA (Non Value Added) activities were recognized and viable measures for development were taken. By implementing the standard operating procedure, the total cycle time has been reduced by $18 \%$, from 170 minutes to 140 minutes [12].

\section{CONTRIBUITION}

\subsection{Foundation of the contribution}

To mitigate the waste emitted in the transport of material, due to unnecessary routes; dust not absorbed by the cyclone dust extractor, due to its low availability; and the emission of waste, due to the variability in working methods, direct applications were investigated in similar companies

As mentioned in the State of the Art, several studies and / or case studies have been found in which tools such as SLP, Lean manufacturing, Standardization of work methods and Scheduled maintenance plans have been proposed and / or implemented. Each of these applications has one or more approaches in the organization, which may be related to the dimensions of waste reduction, human capital, process control and effort reduction.

\subsection{Proposed Model}

Taking into consideration the dimensions in the previous point, the general view of the proposed model is shown in Fig. 1. In which the 4 dimensions already mentioned are aligned, in addition to showing the phases for its development and implementation.

\subsection{Specific View}

Waste Reduction: This dimension is directly aligned to the problem of the case study, since it is determined from the emission of waste from handling, material transport and unavailability of the cyclone dust extractor, due to bad work practices, maintenance and plant layout.

Process Control: This dimension is related to the conservation, control and measurement of the processes 


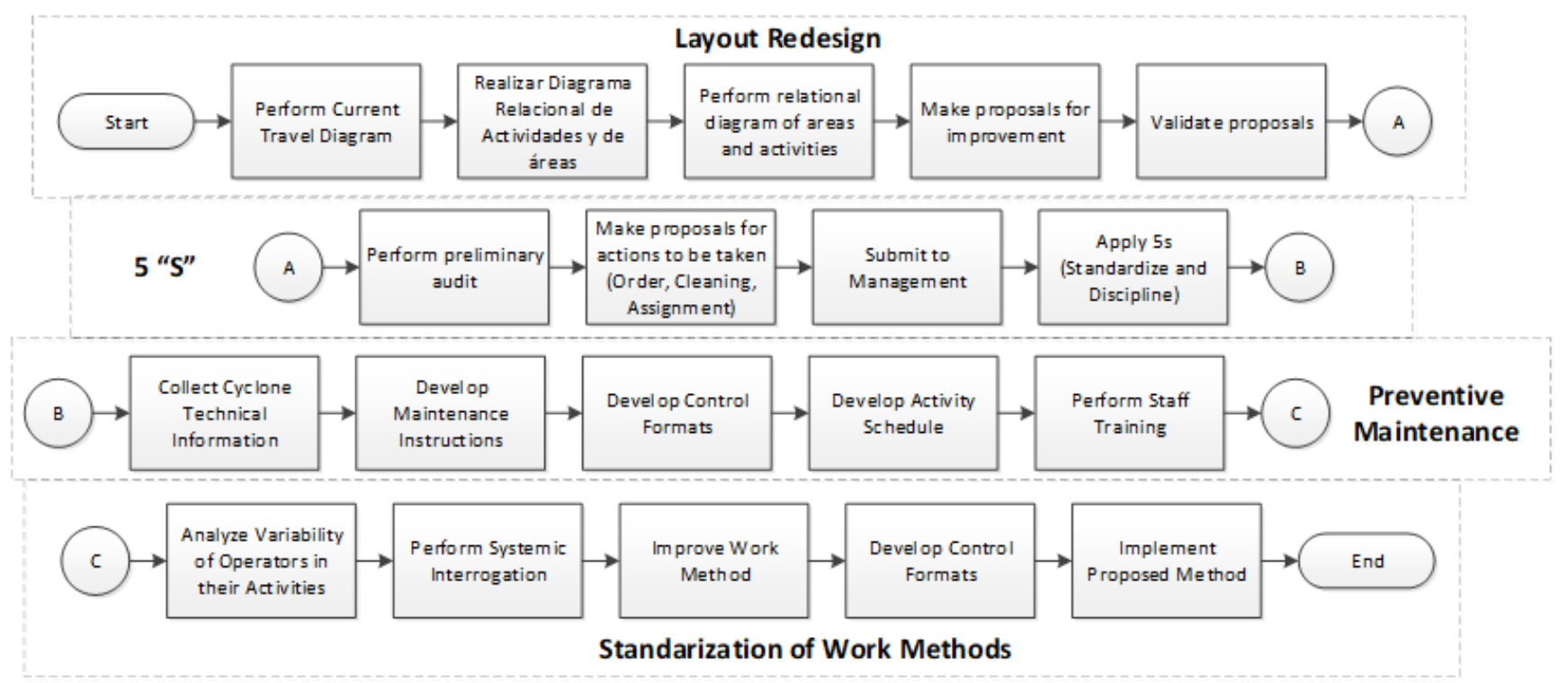

Fig. 2 Proposed Implementation Flow

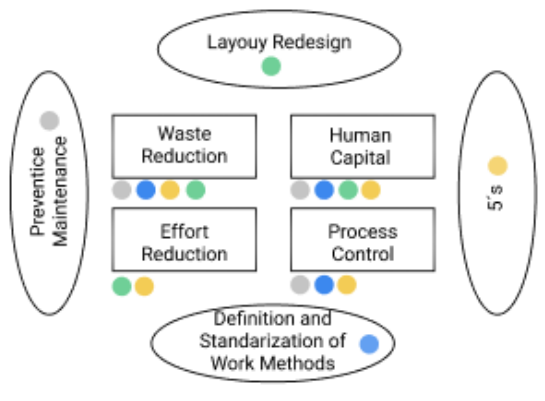

Fig. 1 Proposed model

involved within some of the phases of the proposal, so that the information record for their respective documentation can be monitored.

Reduction of efforts: This dimension is not directly related to the waste generated, however, it should be noted that it depends on the level of effort and working conditions to maintain the best performance of the collaborator in the activities related to production, which if they are seen involved in the causes of bad work practices.

\subsection{Proposed Method}

Fig. 2 shows the detail of the flow to implement the proposal, in which it is proposed to start by Layout Redesign. Once the areas are in the right place then an audit should be carried out to propose improvement with the 5 s philosophy. Once the ideal physical state of the components of each area has been determined, technical information necessary to propose preventive maintenance manuals to the dust extractor cyclone should be collected. At the same time, the analysis of variability in the execution of the operations by the operators in the preliminary crushing of calcium carbonate can be carried out, so that the best procedure is chosen and to perform a systemic interrogation, which will allow to improve and propose the method to standardize.

\subsection{Achievement indicators}

Below are some indicators to take into account in the proposal, which will be responsible for measuring improvements in waste of raw material in production processes, the units of the variables are in tons.

- Waste in Material Transportation:

Equation (1) measured the reduction of waste generated in shipments of raw material and material in process, comparing the current emitted waste with the waste once Layout redesign has been carried out.

$$
\frac{\text { Waste } 1-\text { Waste } 2}{\text { Waste } 1} \times 100
$$

- Material not absorbed by the Cyclone:

Equation (2) measured the reduction of particles not absorbed by the cyclone, which is directly linked to its availability. It will be determined by comparing the amount of current non-absorbed particles with the amount of nonabsorbed particles once preventive maintenance has been implemented.

$\frac{\text { Not Absorbed Material } 1-\text { Not Absorbed Material } 2}{\text { Not Absorbed material } 1} \times 100$ 


\section{- Material Wasted in Prior Break:}

Equation (3) measured the reduction of waste generated in preliminary crushing, comparing the current emitted waste with the waste once the standardization of the improved working method has been carried out.

$\frac{\text { Wasted Raw Material } 1-\text { Wasted Raw Material } 2}{\text { Wasted Raw Material } 1} \times 100$

\section{VALIDATION}

\subsection{Case Study}

The study case is carried out in a company of the heading, which since 2007 is dedicated to the grinding of industrial rocks in different grain sizes (non-metallic mining), such as: calcium carbonate, bentonite and chalk. These products are produced and distributed at the request of the client in different markets such as: Production of paintings, production of ceramics, production of food and products for animals, etc. Its main clients are chicken breeding companies (La calera and San Fernando), manufacturing companies for temple paint (Tekno).

It is currently located in the Luringancho district in the province of Lima. The main product of this company it is calcium carbonate representing $87.7 \%$ of annual production, selling in the period from March 2018 to February 2019 approximately 2980 tons.

The company has a problem with the emission of waste in its operations, which was validated by comparing the tons entered versus the tons produced. This mayerial loss represents 66.6 thousand soles per year of unused material, representing $10.1 \%$ of waste. This percentage exceeds $5 \%$ of standard waste of companies engaged in the same activity.

\subsection{Diagnosis}

The problem of material waste above $5 \%$ is due to the following causes: loss in the process of previous breakage, which represents $12.7 \%$ of the total waste; loss in transport of material, which represents $17 \%$ of the total waste; other reasons without cause found that represent $17.3 \%$ of the total waste and losses due to the stopping of the suction cyclone that represent $10 \%$ of the total waste.

\subsection{Proposed Solution}

\subsubsection{Layout Redesign}

From the relational diagram of activities, the Relational Diagram of areas could be carried out, in which the current and related areas are shaped using line formats according to the level of relationship they have, as shown in Fig. 3.

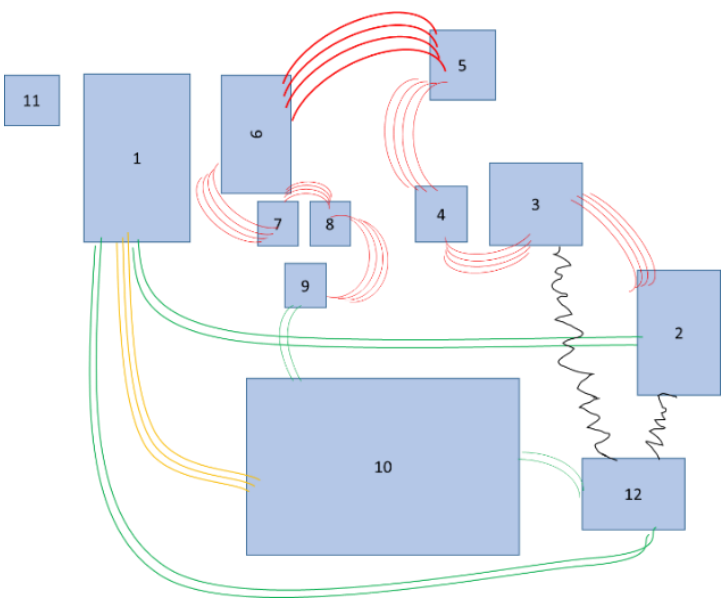

Fig. 3 Relational Areas Diagram

Once the relational diagram of areas was made, the new layout was proposed, shown in Fig. 4, where modifications were made regarding the dimensions of areas and transfers of areas according to the relational diagram of areas.

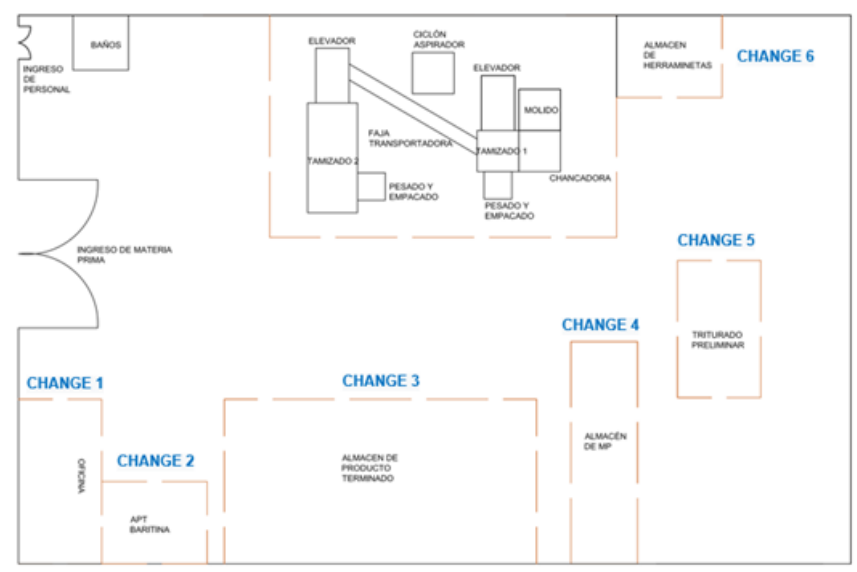

Fig. 4 Proposed Layout

A 2D simulation was carried out, with which we could validate that the layout redesign was able to eliminate one of the routes that represented the greatest amount of waste, and somehow, indirectly with the help of the phases of the proposal, the grams of waste were reduced in other routes and material handling. Table I shows the average material lost in material transfers by truck, which is reduced indirectly thanks to the $5 \mathrm{~S}$ proposal, at the same time only two routes are identified compared to Table I. These data determine the waste that is generated once the proposal is implemented, reducing waste from 46.1 tons / year to 16.3 tons / year, generating savings of approximately 6.8 thousand soles. 
TABLE I

Proposed Waste Matrix

\begin{tabular}{lccc}
\hline \multicolumn{1}{|c}{ Route } & Transfers & $\begin{array}{c}\text { Waste per } \\
\text { transfer }(\mathrm{g})\end{array}$ & $\begin{array}{c}\text { Total Waste } \\
\text { (t) }\end{array}$ \\
\hline $\begin{array}{l}\text { (2) From Trituration Area } \\
\text { to Crusher }\end{array}$ & 9022 & 73 & 0.65 \\
\hline $\begin{array}{l}\text { (3) From the trommel to } \\
\text { the finished product } \\
\text { warehouse }\end{array}$ & 6767 & 104 & 0.94 \\
\hline
\end{tabular}

\subsubsection{Definition ande Standarization of Methods}

Training and delivery of formats for the realization of the pilot of working methods was carried out. An initial 3-hour training was carried out with the operators. Subsequently, a control and measurement were carried out by the production manager of the new times and waste for the pilot. Fig. 5 demonstrates the method standardization training.
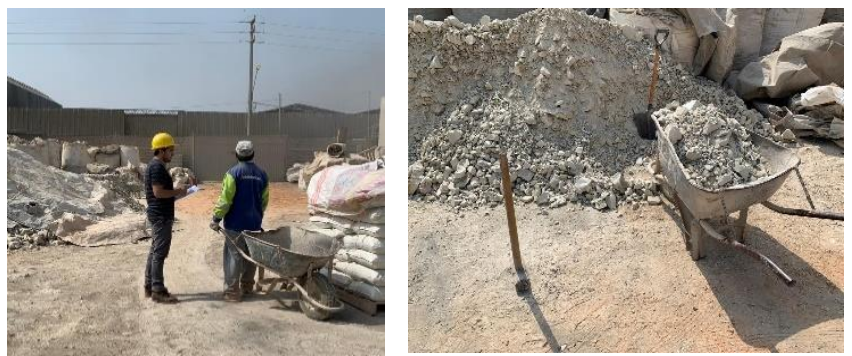

Fig. 5 Standarization of Methods Training

For the validation of waste reduction, the plant manager monitored ten measurements per operator per day for 45 days, and filled out this method format.

The objective of this pilot was to measure the reduction of waste by standardizing the process of pre-breaking the rock. The old method can be seen in Table II and the new method in Table III.

With the data obtained by the Production Manager, we can compare the new results of the method with the previous ones, as shown in Table IV.

Taking into account that the average material waste in the pre-breaking process initially was $1.25 \mathrm{~kg}$. We can say that (4)

$$
P=\frac{1.25 t n-0.375 t n}{1.25 t n} \times 100=70 \%
$$

where $P$, is the reduction of waste compared to the diagnosis of the company.
TABLE II

INITIAL WASTE MATRIX

\begin{tabular}{|c|l|c|c|c|}
\hline \multicolumn{4}{|c|}{ INITIAL SITUATION - PRIOR ROCK CRUSHING PROCESS } \\
\hline$\#$ & \multicolumn{1}{|c|}{ Activity } & Time (min) & $\begin{array}{c}\text { Distance } \\
\text { (m) }\end{array}$ & $\begin{array}{c}\text { Waste } \\
\text { (kg) }\end{array}$ \\
\hline 1 & Temporary warehousing & 0 & & \\
\hline 2 & $\begin{array}{l}\text { Transfer to temporary } \\
\text { warehouse }\end{array}$ & 2.5 & & \\
\hline 3 & Visual inspection of rocks & 3 & & \\
\hline 4 & Wheelbarrow material loading & 4 & & \\
\hline 5 & Transfer to prior crushing area & 2 & & \\
\hline 6 & Wheelbarrow material loading & 2 & & \\
\hline 7 & $\begin{array}{l}\text { Rocks crushing with camber } \\
\text { and rocks inspection }\end{array}$ & 27 & & \\
\hline 8 & Wheelbarrow loading & 5 & 50.4 & \\
\hline \multicolumn{2}{|r|}{ TOTAL } & 45.5 & & 1.25 \\
\hline
\end{tabular}

TABLE III

PROPOSED WASTE MATRIX

\begin{tabular}{|c|c|c|c|c|}
\hline \multicolumn{5}{|c|}{ TEST PILOT - PROCESO DE ROTURA PREVIA DE LA PIEDRA } \\
\hline \# & Activity & Time (min) & $\begin{array}{c}\text { Distance } \\
\text { (m) }\end{array}$ & $\begin{array}{c}\text { Waste } \\
(\mathrm{kg})\end{array}$ \\
\hline 1 & Inspection of wheelbarrow & 3 & & \\
\hline 2 & Rock crushing with camber & 25 & & \\
\hline 3 & Stir Material With Shovel & 3 & & \\
\hline 4 & $\begin{array}{l}\text { Crushing with camber and } \\
\text { chisel }\end{array}$ & 3 & & \\
\hline 5 & Wheelbarrow loading & 5 & 1 & \\
\hline & TOTAL & 45.5 & 1 & 0.374 \\
\hline
\end{tabular}

TABLE IV MEASUREMENT RESULTS

$\begin{array}{cccc}\text { Operator } & \text { Average } & \text { Average } & \text { Average } \\ \text { Time }(\mathrm{min}) & \text { Distance }(\mathrm{m}) & \text { waste }(\mathrm{kg})\end{array}$

\begin{tabular}{lccc}
\hline Operator 1 & 34 & 1 & 0.38 \\
\hline Operator 2 & 35 & 1 & 0.367 \\
\hline Operator 3 & 36 & 1 & 0.386 \\
\hline Operator 4 & 35.5 & 1 & 0.37 \\
\hline Average & & 1 & 0.375 \\
\hline
\end{tabular}

\subsubsection{Preventive Maintenance}

Once the preventive maintenance instructions for each component of the dust extractor cyclone were implemented, as well as the check lists for their respective control, a pilot was made, which showed us the availability index with a result of $83 \%$, because the stops for the cleaning of sleeves to carry out the preventive maintenance are considered unplanned stops, since they stop absorbing material. The production index results 
in $98 \%$. This result improved because now the sleeves are restored every two hours, although it is true that $100 \%$ is not reached, but an improvement in productivity has been achieved. The quality index is maintained at $100 \%$ because all the absorbed powder is carbonate, since it is directly connected to the mill. Table $\mathrm{V}$ shows the aforementioned indicators.

TABLE V

PROPOSED OEE INDICATORS

OEE CALCULATION

\begin{tabular}{lcc}
\hline & & \\
TOTAL TIME (min) & A & 11520 \\
TIME OF PLANNED STOPS (min) & B & \\
AVAILABLE TIME (min) & $\mathrm{C}=\mathrm{A}-\mathrm{B}$ & 11520 \\
TIME OF UNPLANNED STOPS (min) & $\mathrm{D}$ & 1920 \\
OPERATION TIME $(\mathrm{min})$ & $\mathrm{E}=\mathrm{C}-\mathrm{D}$ & 9600 \\
AVAILABILITY INDEX & $\mathrm{F}=\mathrm{E} / \mathrm{C}$ & $83 \%$ \\
\hline & & 11760 \\
TOTAL PRODUCTION $(\mathrm{kg})$ & $\mathrm{G}=\mathrm{BUENA}+\mathrm{K}$ & 1.25 \\
THEORETICAL SPEED $(\mathrm{kg} / \mathrm{min})$ & $\mathrm{H}$ & 12000 \\
THEORETICAL PRODUCTION $(\mathrm{kg})$ & $\mathrm{I}=\mathrm{E} * \mathrm{H}$ & $98 \%$ \\
PRODUCTION INDEX & $\mathrm{J}=\mathrm{G} / \mathrm{I}$ & \\
\hline
\end{tabular}

REJECTED PRODUCTION (KG)
QUALITY INDEX

TOTAL EFFICIENCY
$\mathrm{K}$

$\mathrm{L}=(\mathrm{G}-\mathrm{K}) / \mathrm{G}$

$\mathrm{F} * \mathrm{~J} * \mathrm{~L}$

$81.7 \%$
These 3 indicators give us as final result an OEE of $81.67 \%$, which is classified as Acceptable. This means that it represents slight economic losses, they translate into approximately 2.4 tons per month and approximately 28.8 tons per year in material not absorbed approximately per year, reducing the amount of dust not absorbed by $47 \%$.

\section{DISCUSSIONS}

\subsection{Scenario 1 (Layout Redesign)}

Once the 2D simulation of the new distribution of (new layout) plant was carried out to reduce or mitigate unnecessary transfers of raw material, product on process and finished product, a waste reduction of $65 \%$ was obtained. In the initial diagnosis, waste was measured in the previous breakage process of 46.1 tons / year and using the percentage of waste reduction validated in the pilot of the flow in the new plant layout proposed, waste of 16.32 tons / year is projected, as shown in Fig. 6

\subsection{Scenario 2 (Methods Redesign)}

After the pilot implementation of the standardization of methods in the process of prior rupture of the rich, a waste reduction of $70 \%$ was obtained. In the initial diagnosis, waste was measured in the pre-breaking process of 35 tons / year ccaused by mishandling of tools and working methods. Using the percentage of waste reduction validated in the simulation simulation of the standardization of the method for the preliminary crushing of the raw material, waste of 10.5 tons / year is projected, as shown in Fig. 7.

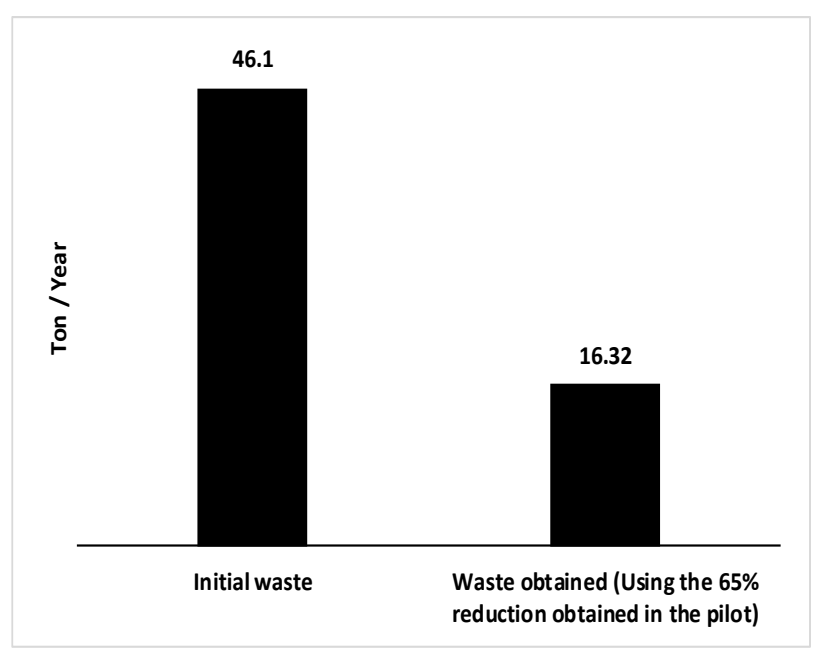

Fig. 6 Waste reduction with layout redesign

\subsection{Scenario 3 (Preventive Maintenance)}

Once the pilot project of preventive maintenance was carried out to reduce the amount of fine dust not absorbed due to the unavailability of the cyclone, a waste reduction in $47 \%$ was obtained. In the initial diagnosis, waste was measured in the process of prior rupture of 54 tons / year and using the reduction validated in the preventive maintenance system pilot, percentage of 28.8 tons / year, as shown in Fig. 8. of 54 tons / year and using the reduction percentage of 28.8 tons / year, as shown in Fig. 8.

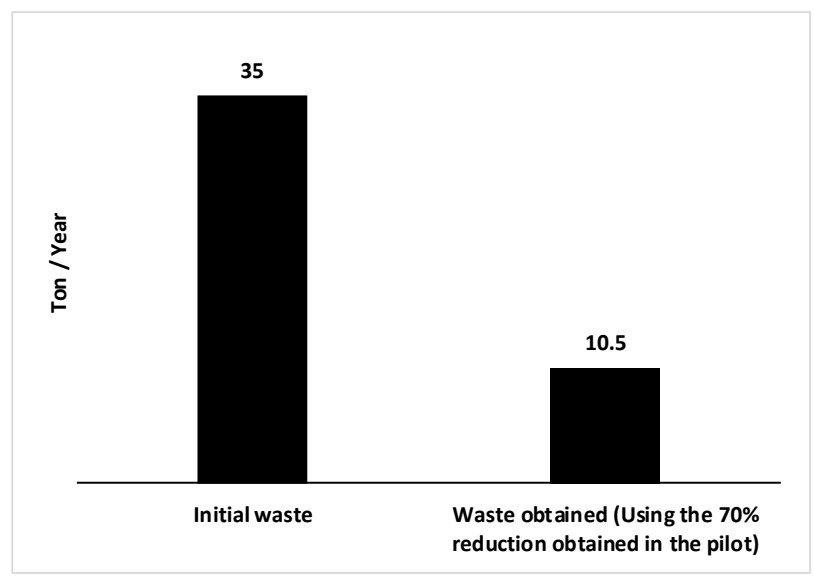

Fig. 7 Waste reduction with methos standarization

\subsection{Future Contribuition}

Future research is recommended to pilot the new prebreaking method for longer because there is a method learning 
curve. This means that the collaborators will improve the execution of the method, which leads to a greater reduction of material waste. In addition, communicate to employees about the main benefits in a quantitative and summarized way of the use of the new work guidelines, so that they become aware of the savings in waste caused by bad practices.

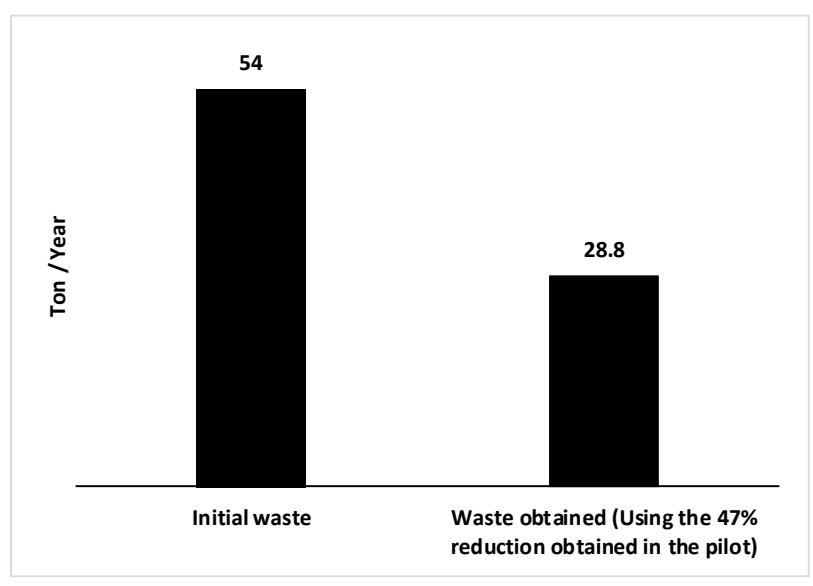

Fig. 8 Waste reduction with prevnetive Maintenance

\subsection{Results Anlysis}

After the validations of the proposed model, the waste reduction results obtained in Table VI were obtained. Expected waste corresponds to the waste that must be reached to reduce the total material waste from the case study from $10.7 \%$ to $5 \%$.

TABLE VI RESULTS ACHIEVED

\begin{tabular}{lcccc}
\multicolumn{1}{c}{ Proposal } & $\begin{array}{c}\text { Actual } \\
\text { Waste per } \\
\text { year }(\mathrm{t})\end{array}$ & $\begin{array}{c}\text { New } \\
\text { Expected } \\
\text { Waste }(\mathrm{t})\end{array}$ & $\begin{array}{c}\text { New Waste } \\
(\mathrm{t})\end{array}$ & $\begin{array}{c}\text { Waste } \\
\text { Reduction } \\
(\%)\end{array}$ \\
\hline $\begin{array}{l}\text { Work Methods } \\
\text { Standarization }\end{array}$ & 35 & 4 & 10.5 & 70 \\
\hline Layout Redesign & 46.1 & 4.5 & 16.32 & 65 \\
\hline $\begin{array}{l}\text { Preventice Maintenance } \\
\text { to the cyclone }\end{array}$ & 54 & 5.4 & 28.8 & 47 \\
\hline
\end{tabular}

It is noted that the expected results were not achieved. However, this is because they were ideal results. In the case of standardization of methods, it is expected to improve the method and reduce waste more as the workers' learning curve stabilizes. In preventive maintenance it is expected that when piloting more time, quarterly and semiannual maintenance can be applied and the dust extractor cyclone stops reduced more. Despite not being able to reduce the 121.2 tons / year of waste, it was possible to reduce 79.48 tons / year.

\section{CONCLUSIONS}

The use of Method Definition and Standardization, Layout Redesign (SLP) and Preventive Maintenance with 5's support was proposed. This in order to reduce material waste in the production process. With the validation performed, results of a reduction of material waste from 135.1 tons / year to 55.6 tons / year were obtained.

In the analysis of the company's problems, it was found that material waste is $10.7 \%$ (298 tons / year or 61,500 soles / year) of the total material entering the production process. These wastes are made up of handling losses in productive process (47\%), material lost in stops of the cyclone dust extractor $(18 \%)$ and waste typical of the raw material on the rock $(35 \%)$. The first two causes were attacked since the third corresponds to the competitive priority of low costs in raw material of the company. It is recommended to expand the investigation of waste reduction with other types of RMI, since the present case focused on calcium carbonate.

An initial audit was conducted 5's where a score of 13 of 50 possible points was obtained. For the 5's proposal, visual management tools were developed, and spaces, managers and key activities were determined. In the pilots of standardization of methods and preventive maintenance, 5's were required in the initial part to delimit.

\section{REFERENCES}

[1] Instituto Geológico, Minero y Metalúrgico (INGEMET), "Potencial, Producción y Comercio de las Rocas y Minerales Industriales del Perú 1970 - 2017.”, Lima, 2017, unpublished.

[2] Miatto, A., Schandl, H., Fishman, T., \& Tanikawa, H.; Global Patterns and Trends for Non-Metallic Minerals used for Construction. Journal of Industrial Ecology. EEUU, 2017.

[3] Ministerio de la Producción, "Resolución directoral N409-2017PRODUCE/DVMYPE/DGAAMI", Lima, 2017, unpublished

[4] M. Zapata, Estudio de pre factibilidad para la instalación de una planta de producción de arena sílice para uso industrila. Lima, 2012, unpublished

[5] Ahmed M. Diab, Abd Elmoaty, Long term study of mechanical properties, durability and environmental impact of limestone cement concrete. Egypto, 2016.

[6] Karen A. Hudson, David Kossoff; Role of Redox-Active Minerals in the Reuse and Remediation of Mine Wastes. Inglaterra, 2017.

[7] Willison, John; Buisman-Pijlman, Femke; An application of 5S concept to organize the workplace at a scientific instruments manufacturing company. India, 2016.

[8] Dunuwila, Pasan Rodrigo; Sustainability of natural rubber processing can be improved: A case study with crepe rubber manufacturing in Sri Lanka. Japón, 2018.

[9] Durakovic, Benjamin; Demir, Rukiye; Lean Manufacturing : Trends and Implementation Issues. Bosnia, 2018.

[10] Richard Palluzi; Best Practices for Pilot Plant Layout. EEUU, 2018.

[11] Jiri Ansorge and Hana Mohelska; Game for a LEAN Methods Training (5S, Visual Management and Standardization of Work). República de checa, 2018.

[12] Nallusamy, Saravanan; Lean tools execution in a small scale manufacturing industry for productivity improvement- a case study (La ejecución de herramientas esbeltas en una industria de fabricación a pequeña escala para la mejora de la productividad: un estudio de caso)"; 2016.

[13] Fawaz A. Abdulmaleka, Jayant Rajgopal; Analyzing the benefits of lean manufacturing and value stream mapping via simulation: A process sector case study. EEUU, 2015.

[14] Pakdil, Fatma; Toktaş, Pelin; Leonard, Karen Moustafa; Validation of qualitative aspects of the Lean Assessment Tool (LAT). EEUU, 2018. 
[15] Miller, Geoff; Pawloski, Janice; Standridge, Charles; A case study of lean, sustainable manufacturing (Un estudio de caso de manufactura esbelta y sostenible). Journal of Industrial Engineering and Management. EEUU, 2015.

[16] Lopes, Borges, Freitas, Sousa; Application of Lean Manufacturing Tools in the Food and Beverage Industries. Chile, 2015.

[17] Palluzi; Best Practices for Pilot Plant Layout. Chemical Engineering Progress. EEUU, 2018.

[18] Antoniolli; Standardization and optimization of an automotive components production line. Procedia Manufacturing. España, 2018.

[19] Prabhuswamy; Total Productive Maintenance (TPM): An Operational Efficiency Tool. International Journal of Environmental Science and Technology. India, 2018.

[20] Sharma; Impact of lean practices on performance measures in context to Indian machine tool industry. Journal of Manufacturing Technology Management. India, 2016. 